\title{
Analysis on Artistic Characteristics of Vernacular Architecture in Henan Regional Culture
}

\author{
Yanan Yang \\ School of Art and Design \\ Huanghe Science and Technology College \\ Zhengzhou, China
}

\begin{abstract}
The most common and representative vernacular architecture in Henan is traditional courtyard houses. Its decorative structure is of both the southern and northern forms with various types. Its materials are selected according to local conditions, integrating the rule of artful beauty in form and carrying the most essential spiritual belief of agricultural culture of the central plain, which is one of the typical examples to learn about traditional Henan settlement environment.
\end{abstract}

Keywords - traditional Henan courtyard houses; component characteristics; formal beauty

\section{INTRODUCTION}

Located at the central plain, Henan is a place of wealthy with dense population in all the past dynasties. Architectural groups of various sizes such as villages and city walls exist on this land with their own unique form, shaping the traditional settlement environment which represents central plain culture.

The geographical characteristics of traditional Henan courtyard houses are closely related to cultural characteristics of the central plains. An old saying goes: "Henan is certainly to be fight for conquering the world", which is indispensable from the unique advantages of geographical conditions of Henan and its significant social, political and economic status. As Henan is located at the marginal area of interlaced region of Chinese warmtemperate zone and subtropical climate, its climate is of obvious transitional features. Xinyang, Nanyang and some areas of Zhumadian belong to the climate zone of subtropical humid areas and sub-humid areas; central and eastern part of it is alluvial region of Huang-Huai-Hai Plain; there are plenty mountains and hills in western and southern part with many strategic passes, which is the throat land for westward and southward. With a centered geographical position and convenient transportation, Henan settlements are of both the southern and northern forms with various types to adapt to different landforms, landscapes and material selection according to local conditions.

\section{CHARACTERISTIC COMPONENTS OF VERNACULAR ARCHITECTURE}

Most of the folk religions carry the primitive fetishism

This paper is one of the research achievements of Study on Current Situation of Traditional Settlements in "Four-Kind Communities" of Zhengzhou New-type Urbanization (141PXKXF612) of Henan Zhengzhou Soft Science Research Project Presided by Yang Ya'nan. characteristics, and the Earth God, Door God and Kitchen God are holding a more important position in residential life. Through these worship and rituals, people seek peace and health to realize their good wishes such as favorable weather, bumper grain harvest and prosperous both in family and purse. The existence of Gods has formed an integral part of people's traditional spiritual life, and it has provided extensive materials for architectural components as well.

\section{A. Shrine}

Most of the traditional settlements will serve their own Family Gods, including Deity, Kitchen God, God of Wealth and Door God and other gods besides the memorial tablets of their ancestors. The locations for those Gods are flexible, all the Gods can be placed on the gable wall, screen wall and door opening, except the memorial tablets of their ancestors shall be placed in the main hall. For example, in each courtyard of Kang Baiwan Manor, the arch-shaped small niches can often be seen in the front wall of main caves, serving as a small altar to warship Deity and Earth God at holidays and festivals; in the courtyard of Zhaipuchang of Bo'ai County, a shrine stands in front of the screen wall.

\section{B. Feng Shui Screen}

Located at the central plain, Henan is the integration point for Confucian culture and Taoism Culture. The simple and honest people here, no matter the wealthy trader or the ordinary people, all follow the rule of low profile and steadfast to deal with affairs, which also applies to the their design of courtyard's entrance. Perhaps for the reasons of "no financial exposure", "bring in wealth and treasure" or even "block or avoid a disaster", the screen walls with the function of shielding are selected for the design of courtyard gate for no matter the grand courtyard or the common house in regional architecture of Henan. As a result, screen wall has been the characteristic architectural components of Henan vernacular houses, especially the courtyard residence, and the decoration position with emphasis representing the master's social status, wealth and power. In addition, the attaching façade, eaves gallery and others have also been the details for the decoration therein. Corresponding material and decorating techniques will be selected according to the master's social status and wealth, and the overall decoration will be conducted through regional decorative symbols that represent good intentions, forming an accessorial building 
with rich style at the entrance, which is a reflection of the richness of detail landscapes in traditional courtyard houses.

For example, in the area of Luoyang, a shrine will be built on most of the screen walls for worshiping of Earth God. Calligraphy and paintings are inserted and engraved in the screen walls, including such auspicious patterns as Longevity Crane, Ma Gu Xian Shou, Sika Deer Looking at Cypress, a huge overlapping word of "Fu"(means blessing) and "Shou"(means longevity) may be engraved on some of the walls.

\section{Parapet}

Parapet is commonly used in flat-roofed houses and cave dwellings. The parapet of cave dwelling is the low wall built on the top of cave's front wall, and it is a maintenance component for keeping out the rainwater from the front wall and for prevention of people and livestock to fall off from top of the cave. It is the top skyline of cave dwelling houses, and the part below parapet that connecting with front wall is the eaves shed (board) for protecting the wall. Generally, it is built with adobe or brick, or embedded with rubble. It will be built into various types of tracery wall when using bricks and the rubble will be used to decorate the front of the cave with various patterns formed together with grey tiles and grey bricks, which pays attention to beautification and decoration.

\section{Eaves Gallery and Brick Carving}

Eaves galleries are generally built in front of the important central room or the brick or stone arch caves for wealthy and influential families. Eaves gallery not only expands the protection of eaves, but also forms a transitional space between courtyard and living room. In addition, it adds spatial levels in terms of façade, generating plentiful light and shadow changes, and becomes a decorative element as well. Such cave dwellings with eaves galleries include brick eaves gallery, for example, the arcade of west courtyard Liu Maoen Manor in Gongyi.

\section{Façade Wood Carving}

The upper part of the cave gate is often carved finely and elaborately with emphasis, which is named as façade. As for the cave dwellings in western Henan, patterns of tassels and curtain will be carved in general families, and the arched door is decorated with the overlaid floriation brick carving to add the lace beauty of arch curve. Generally, the theme includes such horizontal inscribed boards as Five Blessings and From East Comes Auspicious Air. Small door eaves are overlaid with brick above the arch curve, and there are multilayers such as water brick, two-side continual textured brick and bamboo brick carvings. In order to keep out wind and rain against the front of the cave, water milled thin bricks are used to make both ends of the upward side scroll up. For example, round hole is often made by hexagon bricks on the small canopy in western Henan, forming an exhaust port besides its function of decoration.

In addition, the chapiter at lower end of festoon gate is one of the key sections for wood carving decoration. Basic forms of chapiter can be divided into round chapiter and square chapiter. The theme for round chapiter carving is lotus, which looks like a lotus in bud.

Another section where the wood carving often appears is the wall of bracket eye above the door. The carving at this section is mainly openwork carving with exquisite way of cutting. For instance, the lion rope woodcarving on the gate of Kang Baiwan Manor looks like the real object as three lovable lions are climbing on the rope to capture the silk ball in the middle. "Red Phoenix in Morning Sun" made of peacock and peony is surrounded by Ruyi shaped cloud with the Ding as a center. There are many wood carvings in traditional architecture which are similar to the abovementioned, and each work contains the craftsman's infinite imagination and the spirit of worshiping traditional culture.

\section{E. Masonry Carving}

In traditional residential buildings, stone is often used as a support, yet the stone carving may be an important component in the architecture. Stone carving and wood carving in traditional architecture are of both the function of using and decorative effect and cultural connotation. Thanks to its hard texture and the characteristics of wear-resisting and anti-corrosion, stone carvings often appear at the key and prominent section in the building. Generally, the stone carving components placed outside will be processed elaborately, making an artistic work with strong decorative arts.

Stone carving can be divided into three-dimensional portraits, animal statues, chapiters and others in terms of three-dimensional stone carving. And it can be divided into emboss, openwork carving pane, lettering plaque, stone carving, shadow engraving, line engraving and so on in terms of plane stone carving. Masonry carving is the most frequently used decoration method in residential buildings, which is a reflection of the vernacular and artistic residential buildings.

There are abundant themes for carving decoration which include animals, plants, characters, birds and beasts, traditional Chinese opera stories, historic legends etc., expressing people's living pursuit and aesthetic preferences. The various stone carvings and wood carvings in Wang's Courtyard of Zhaipuchang Village in Jiaozuo are carved with exquisite workmanship possessing strong cultural atmosphere. The hangings and pendants below the eaves are carved exquisitely with plentiful themes such as flowers, birds, fishes, insects as well as immortals and beasts and so on. Moreover, the two Chinese characters of "Geng Du" (means farming and reading) are carved on the special eaves tiles at the corner of eaves of the house, indicating the master's ideological pursuit fully with extreme features. For example, there are 30 Flowers and Birds Pictures in six groups on the stone sill of window in the 37th yard of Kang Baiwan Manor: elegant peony and vivid magpie. Those stone carvings are carved with fluent and clear line, forming the rare boutique in traditional residential buildings. 


\section{FORMAL BEAUTY RULE OF HENAN VERNACULAR ARCHITECTURE}

Traditional residential decoration is characterized by rich types and free composition with decorative style of simple and modest, capriccioso, elegant and pure, luxurious and flashy which is more extensive than the decoration of official architecture. The architectural complex of Kang Baiwan Manor are of vivaciousness and freedom of residential buildings as well as the normalization and perfection of the layout planning of official architecture, with precious decoration and color processing skill. And the decoration for detail parts of them has reached the level of high perfection, possessing an overall style of serious and tolerant as well as precise, luxury and elegant.

\section{A. Refection of Symmetry and Balance}

Symmetry, also called "peer to peer", is the absolute balance made up by the fitting syntagmatic relation among the same or similar elements, and is an absolute manifestation mode of law of equilibrium. Symmetry can be divided into central symmetry, symmetry of axis lines and plane symmetry. The symmetrical form may bring about pleasure for people, and the symmetrical and balanced layout generate such artistic effects as solemn, serious, grandeur and simple. Balance can also be called "equalization", which is the relationship of unity and opposition among various similar elements. Symmetric layout is generally adopted for architectural composition, which is of high stability. And balance can also reach the requirements for stability in asymmetric space or decoration form.

1 ) Symmetry of Spatial Layout. The spatial sequence of traditional residential buildings is mainly realized by the group combination of the courtyards. Especially the transition relations of space generated through passage, lane and door, as well as the spatial function conversion have formed the wonderful courtyard spatial sequence. The buildings in Kang Baiwan Manor are mainly the two-storey hard mountain buildings, with the architectural sequence spread gradually from west to east. The layout of each dependent courtyard is conducted according to the traditional Chinese architectural layout of "Give priority to the vertical axis, and take horizontal axis as complementary", which is applied to the first to the fifth yard at the northernmost main settlements, forming a special quadrangle courtyard form with the combination of quadrangle courtyard and cave dwellings.

The architectural complex and environment are mainly at a balanced state of axial symmetry from the perspective of spatial layout, while generally they are mirror-style longitudinal axis symmetry. And such symmetry is not absolute symmetry as they follow the traditional concept of "high east and low west" in terms of building height, therefore, the wing-rooms in the courtyard present a state of high east and low west due to that concept.

2 )Symmetry of Decoration Form. In view of the background of Kang Baiwan Manor, buildings within the manor are of dual characteristics of official architecture and folk building. Overall layout of the building is unified symmetry, and symmetric layout and symmetric decoration form are adopted for the decoration of exterior and interior eaves of the buildings. For example, the stone carved bearing stone, wood carved sparrow brace, and the brick carved pillar head of hard gables.

\section{B. Exhibition of Variety and Unification}

Comparison and unification are the basic rule for formal beauty and the formal beauty law to be followed by various artistic categories. The so-called variety refers to the differences exist in the form of architectural decoration; and unification refers to the common characteristics of each decoration form and the relations of certain relevance, echoing and set off among them. All variety without unity will appear to be disorganized, and all unity without changes will appear to be rigid and monotonous. Changes are requisite no matter for variety or unification. Expressing beauty of unification from changes and the inner harmonious relations of unified decoration are the allegoric contents to fully express their unification in essence and their uniqueness.

In the architectural complex of Kang Baiwan Manor, as for the single building in each yard, the architectural character and decoration contents are not the same due to their different using functions. The modeling differences among each single building can be seen from the decoration modeling of each single building, and the comparison in terms of form, color, texture and others of the decoration form, but the cultural connotation expressed by the decoration form and the master's spiritual pursuit are implying unification. In addition, subtle changes will exist in the modeling of architectural decoration, for example, the decoration for roof curve, side footing and backing of the building body and the ends of components, especially the expression mode of various decoration components reflecting on architecture are symmetry yet with different contents.

\section{Control of Proportion and Dimension}

Proportion refers to the quantitative relation between overall and part of an object, and between its parts. All the objects get their appropriate proportion within a certain scale range. The beauty of proportion is also generated in the dimension which is standard and norm, including the law of characteristic beauty of the object itself. However, the size of human body is the basic dimension and internal factor to measure other object's proportional beauty. Proportion is not invariable, but through changing of ratio, special artistic effects will be generated. For example, the decoration on wall surface of manor architecture.

\section{Harmony of Rhythm}

From the decoration of the courtyards of Kang Baiwan Manor and the decoration of architecture itself, it can be seen without difficulty that there is sense of rhythm separated by doors between the sequentiality and space of architectural space. From the outer space to indoor of the building, and to the lane with function of transition and combination of space, to the gate of yard and the floor cover with the function of screen, all make the space convey a spatial feeling of 
cadence and actual situation alternating with virtual things. The architectural form and the form of decoration on architecture of single building in each yard are uniform with small variation to reach the requirement of sense of rhythm. For example, just small adjustments are conducted for the decoration form of the gates in various yards in the architectural complex of Kang Baiwan Manor to make the whole courtyard display a cadence while making space transition.

\section{CONCLUSION}

Under the background of urbanization with regional characteristics, the update methods of traditional architecture include multilayer connotations such as protection, development and innovation. And that requires the architects to be integrated into the trend of times, to absorb the excellent architectural culture within Henan province. In addition, they shall protect the excellent architectural cultural heritage, explore local cultural characteristics, infuse traditional essence into modern architectural design, and guide into the contents of modern life, to show loving care for human and satisfy human's spiritual demand, creating an emotional space identified by the masses.

\section{REFERENCES}

[1] Liu DunZhen. History of Ancient Chinese Architecture [M]. Beijign: China Building Industry Press, 1984.06

[2] Zuo Manchang, Bai Xianchen. Study on Residential Buildings in Henan [M]. Beijign: China Building Industry Press, 2007.04

[3] Jing Qimin, Zhang Li'an. Chinese and Foreign Traditional Dwellings [M]. Tianjin: Baihua Literature and Art Publishing House, 2004.01

[4] Literature and History Compilation Committee of Kang Baiwan Manor. Kang Baiwan Manor [M]. Hongkong: Hongkong International Press, 2002.04

[5] Wang Zhili. Traditional Chinese Vernacular Architecture [M] Jinan: Shandong Science and Technology Press, 1994

[6] Liu Dunzhen. General Introduction on Chinese Residence [M]. Tianjin: Baihua Literature and Art Publishing House, 2004.01

[7] Sun Dazhang. Study on Chinese Vernacular Building [M]. Beijign: China Building Industry Press, 2004.08 